\title{
Feasibility of ultrasound measurement in a human model of acute compartment syndrome
}

\author{
Jakob Mühlbacher ${ }^{*^{*}}$ D, Reinhard Pauzenberger ${ }^{2}$, Ulrika Asenbaum ${ }^{3}$, Tobias Gauster ${ }^{4}$, Stephan Kapral ${ }^{5}$, \\ Harald Herkner ${ }^{6}$ and Andreas Duma ${ }^{7}$
}

\begin{abstract}
Background: Early diagnosis of acute compartment syndrome (ACS) of the leg is essential to improve the outcome. Direct invasive measurement is currently recommended to measure intracompartmental pressure. A noninvasive and reproducible means of making the diagnosis would be a step forward. The purpose of this exploratory study was to investigate the feasibility of non-invasive ultrasound-guided angle measurement as a surrogate of increased pressure in a model of ACS.

Methods: A model of ACS was generated by infusion of saline into the anterior compartment of the leg of human cadavers to incrementally increase the intracompartmental pressure from 10 to $100 \mathrm{mmHg}$. In 40 legs (20 cadavers), the angle (TFA, tibia-fascia angle) between the anterolateral cortex of the tibia and the fascia of the anterior compartment was measured at each $10 \mathrm{mmHg}$ pressure increase using ultrasound in a standardized transversal plane. A multilevel linear regression model was used to estimate intracompartmental pressure from delta TFA $(\triangle T F A)$.

Results: TFA (mean $[ \pm \mathrm{SD}])$ increased from $61.0^{\circ}\left( \pm 12.0^{\circ}\right)$ at $10 \mathrm{mmHg}$ up to $81.1^{\circ}\left( \pm 11.1^{\circ}\right)$ at $100 \mathrm{mmHg}$ compartment pressure. Each increase $\triangle$ TFA by one degree was associated with an increase in pressure by 3.9 $\mathrm{mmHg}(95 \% \mathrm{Cl}, 3.8-4.0, p<0.001)$.

Conclusions: We found that intracompartmental pressure of the anterior compartment of the calf can be well estimated by ultrasound-based $\triangle T F A$ in this post mortem experiment. Our findings indicate that non-invasive TFA measurement is feasible and it is reasonable that this will hold true in real life, but the findings are too preliminary to be used in clinical practice now.
\end{abstract}

Keywords: Acute compartment syndrome, Ultrasound, Lower extremity, Human cadaver

\section{Introduction}

Acute compartment syndrome (ACS) of the lower extremity is a condition of rapidly increasing pressure leading to reduced perfusion below a vital level for muscles and nerves within limited anatomic space [1-5]. Most frequently, ACS results after severe traumatic leg injuries [6, 7]. However, other causes such as arterial injury, vascular occlusion, crush injury or contusion while in an anticoagulation state have been described [8]. Without immediate surgical

\footnotetext{
* Correspondence: jakob.muehlbacher@meduniwien.ac.at

${ }^{1}$ Department of Surgery, Division of General Surgery, Medical University of

Vienna, Waehringer Guertel 18-20, A-1090 Vienna, Austria

Full list of author information is available at the end of the article
}

decompression, nerve lesions, muscle contractures, amputation or even sepsis may occur $[9,10]$. Therefore, early diagnosis is essential to avoid irreversible damage [4, 1115]. Currently diagnosis is based on physical examination [11-14]. Invasive pressure measurement is recommended as an adjunct to clinical examination [13, 14]. Non-invasive alternatives such as near-field spectroscopy, microvascular blood flow, muscle oxygenation and $\mathrm{pH}$, laser Doppler flowmetry, quantitative hardness measurements or compression sonography have been examined but were not feasible for routine diagnosis of ACS [1521]. Ultrasound examination is non-invasive, easy to

(c) The Author(s). 2019 Open Access This article is distributed under the terms of the Creative Commons Attribution 4.0 International License (http://creativecommons.org/licenses/by/4.0/), which permits unrestricted use, distribution, and reproduction in any medium, provided you give appropriate credit to the original author(s) and the source, provide a link to the Creative Commons license, and indicate if changes were made. The Creative Commons Public Domain Dedication waiver (http://creativecommons.org/publicdomain/zero/1.0/) applies to the data made available in this article, unless otherwise stated. 
perform, painless and could be used in addition to invasive pressure measurement [22-25].

We hypothesized that increasing pressure following tissue expansion will shift the fascia away from the plane anterolateral cortex of the tibia in the anterior compartment. So far, the compartment width was evaluated using ultrasound to detect changes in healthy volunteers following exercise [22, 23]. Shifting of the angle between the tibia and the muscle fascia may be visible and quantifiable with 2-D ultrasound. In this exploratory human cadaver study, ultrasound was used to estimate pressure in the anterior compartment of the lower extremity based on changes of TFA (tibia-fascia angle).

\section{Materials and methods}

\section{Study design and objectives}

After local institutional review board approval, an exploratory study in human cadavers was performed. Unmodified adult cadavers, within $24 \mathrm{~h}$ after death, were included. Based on physical examination and medical records, specimen with compartment syndrome, signs of previous surgery, trophic disorders, injuries at lower extremities or known gait abnormality were excluded. Experiments were performed in 40 legs (20 right and 20 left) of 20 human cadavers to measure TFA in the anterior compartment of the lower extremity over several pressure levels.

\section{Experiments and measurements}

After collecting base line characteristics, each leg was marked at predefined points for standardized and repeatable measurement of TFA using ultrasound. An ultrasound transducer (Linear Transducer, Typ HFL38/ 13-6 MHz, MicroMaxx, Fujifilm SonoSite Inc. US, Bothell, Washington, USA) was placed in a $90^{\circ}$ angle to the ventral edge of the tibia (Fig. $1 \mathrm{a}, \mathrm{b}$ ) at the end of the proximal third of the distance from the tibial tuberosity to the intermalleolar line. Five centimeters above and two centimeters lateral to TFA measurement, a 14-gauge cannula was placed into the anterior compartment. This cannula was connected to a P-50 pressure Statham transducer (Gould-Statham Instruments Inc., Bayamon, PR) for continuous compartment pressure monitoring. Signals of the P-50 transducer were amplified using a validated custom instrumentation amplifier (linearity was within $\pm 3 \%$, zero stability showed \pm 1 $\mathrm{cmH} 2 \mathrm{O}, 12 \mathrm{~h}$ observation period). Another 14-gauge needle was inserted five centimeters below and two centimeters lateral to TFA measurement for infusion of $0.9 \%$ saline into the anterior compartment to achieve reproducible pressure levels in the area of sonographic evaluation [26]. Lifting a fluid column elevated the hydrostatic pressure and increased the intracompartmental pressure to desired levels $[27,28]$. In order to compensate post mortem dehydration and to verify functionality, each leg was initially rehydrated by
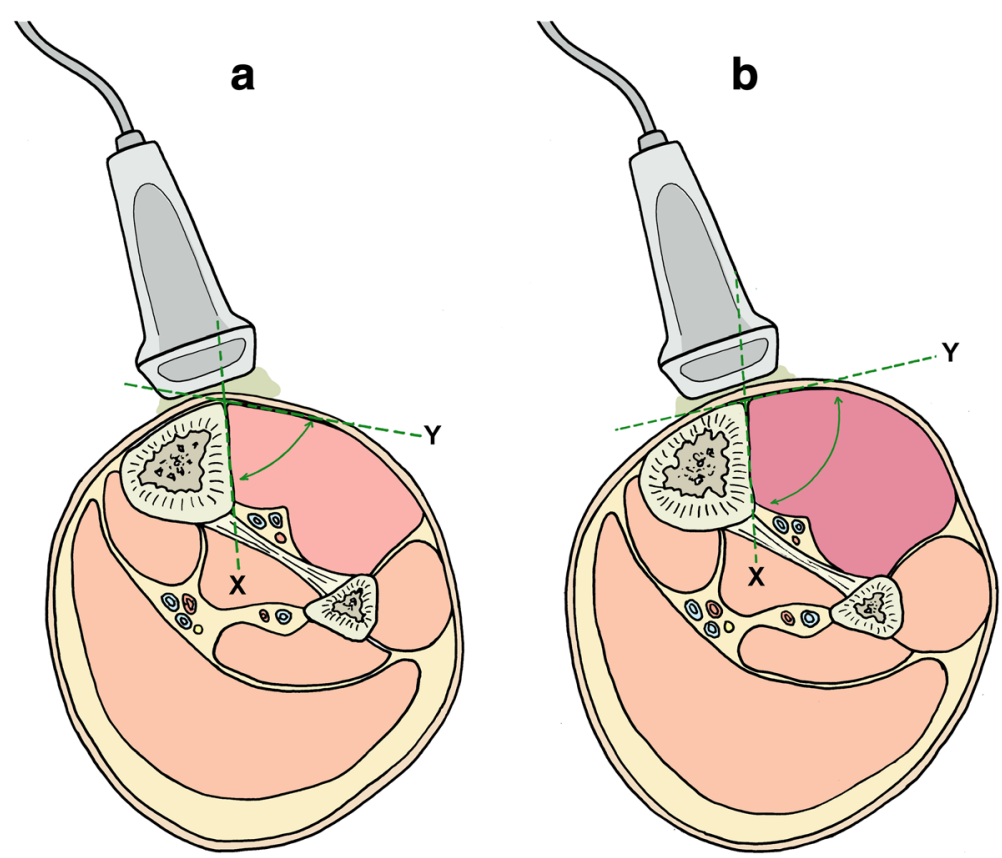

Fig. 1 a, b Schematic illustration of increasing compartment pressure and angle measurement. Schematic illustration of sonographic TFA (tibiafascia angle) measurement. One line $(X)$ was set on the anterolateral cortex of the tibia. The other line $(Y$ ) was set as a tangent to the curving anterior compartment fascia with its origin at the tibial attachment. TFA was the angle measured between line $X$ and $Y$. Measurement under normal conditions (a), enlarged angle in the anterior compartment (b) 
injecting fluid to raise pressure to $100 \mathrm{mmHg}$, which was followed by a passive pressure decrease to $10 \mathrm{mmHg}$ [24]. Afterwards, compartment pressure was again increased in increments of $10 \mathrm{mmHg}$ up to $100 \mathrm{mmHg}$ $[27,28]$. At each pressure level, the tibia-fascia angle (TFA) was measured by means of real-time ultrasound with constant position of the ultrasonic transducer in transversal plain, respectively. Unmodified ultrasound images were stored for subsequent analysis. For TFA measurement, one line was set on the plane anterolateral cortex of the tibia, the other line as a tangent to the curving anterior compartment fascia with its origin at the tibial attachment of the fascia. TFA was the angle between line $X$ and $Y$ (Fig. 1 a, b, Fig. 2).

\section{Statistical methods}

Data are presented as mean \pm standard deviation (SD) or median and $25-75 \%$ IQR for continuous variables and absolute count with a relative frequency for categorical variables. A theoretical cumulative distribution function was fitted to the absolute value of the TFA difference to estimate exceedance probabilities for given quantiles. To access inter-observer variability, $40(10 \%)$ randomly selected (stratified by sex, side, and pressure range) unmodified ultrasound images were analyzed by two independent observers, both experienced in the application of ultrasound; intraclass correlation coefficient (ICC) was calculated. We calculated delta TFA ( $\triangle T F A)$ as the difference of pressure-specific TFA and TFA to the contralateral leg baseline TFA at $10 \mathrm{mmHg}$. By study design, we assumed data to be correlated within individuals and within legs resulting in a multilevel structure. To allow for this, we used a multilevel linear regression model to estimate intracompartmental pressure by $\triangle$ TFA. The model included subject level $(n=20)$, and leg level (right/left) of each 10 measurements at different pressure levels. We performed sensitivity analysis to assess the robustness of our modeling procedure by using multivariable multilevel linear regression models with potentially confounding covariables, polinomial terms, and multilevel ordinal logistic regression. Statistical analysis and figures were done using R (Version 3.3, https://www.r-project.org, Vienna, Austria) and Stata 14 for Mac (Stata Corp., College Station, TX). Generally, a two-sided $p$ value less than 0.05 was considered statistically significant.

\section{Source and funding}

There was no external source of funding for this study.

\section{Results}

Baseline characteristics of human bodies included in the exploratory study are detailed in Table 1 . Within each observed lower leg compartment $(n=40)$, the measured angle increased with rising pressure. Mean $( \pm$ SD) TFA rose from $61.0^{\circ}\left( \pm 12.0^{\circ}\right)$ at $10 \mathrm{mmHg}$ to $81.1^{\circ}\left( \pm 11.1^{\circ}\right)$ at $100 \mathrm{mmHg}$ (Fig. 3). The relation between $\triangle$ TFA and pressure for each individual leg is presented in Fig. 5 in the "Appendix". Comparing legs in each individual at a pressure level of $10 \mathrm{mmHg}$ revealed a low probability of $7 \%$ for an absolute TFA difference of more than $10^{\circ}$

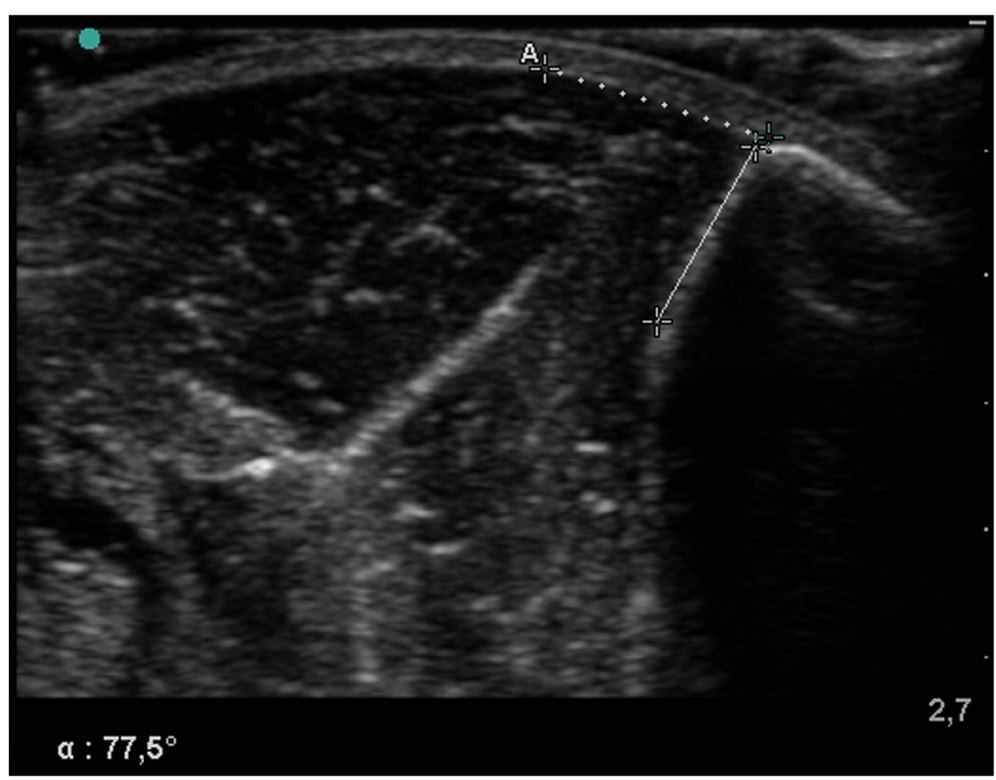

Fig. 2 Ultrasound image of one specimen with measurement of TFA (tibia-fascia angle). Ultrasound image of TFA measurement (male cadaver, right leg) at a generated pressure level of $40 \mathrm{mmHg}$. For TFA measurement one line (solid line) was set on the anterolateral cortex of the tibia and the other line (dotted line) was set as a tangent to the curving anterior compartment fascia with its origin at the tibial attachment. TFA was the angle between the two lines (in this case $77.5^{\circ}$ ) 
Table 1 Demographical data of study subjects

\begin{tabular}{lc}
\hline Parameters & $\begin{array}{c}\text { All study subjects } \\
(n=20)\end{array}$ \\
\hline Baseline data & $81(71-86.3)$ \\
Age, years, median (IQR) & $10(50)$ \\
Female sex, $n(\%)$ & $24.3(22.4-25.7)$ \\
Body mass index, median (IQR) & $29(27-31.5)$ \\
Lower leg circumference ${ }^{a}$, median (IQR) & $31(30-33)$ \\
Tuberosity_intermalleolar distance ${ }^{b}$, median (IQR) &
\end{tabular}

IQR interquartile range

${ }^{a}$ Circumference measured on standardized points $(\mathrm{cm})$

${ }^{b}$ Distance between tuberosity of the tibia and the intermalleolar distance $(\mathrm{cm})$

following the theoretical distribution function, whereas it was less than $10^{\circ}$ in $93 \%$ (Fig. 4). TFA measurement had good inter-observer reliability (ICC 0.77, 95\% CI 0.65 to 0.86$)$. Using the multilevel linear model, we found that between 10 and $100 \mathrm{mmHg}$, a change of one degree in $\triangle$ TFA was associated with a pressure increase of $3.9 \mathrm{mmHg}$ (95\% CI, 3.8-4.0, $p<0.001$ ). Adding age, gender, weight, height, tuberosity-intermalleolar distance and lower leg circumference as covariables to the model left the estimate virtually unchanged. Likewise sensitivity analyses using other modeling strategies indicated robust estimates.

\section{Discussion}

In this exploratory study, we investigated the feasibility of ultrasound-guided measurement of TFA, the angle between the rigid anterolateral cortex of the tibia and the fascia, as a surrogate parameter for increased pressure in the anterior compartment of the lower extremity in a human cadaveric compartment syndrome model. Reproducible pressure levels could be generated in the anterior compartments, and sonographic measurement of the TFA was feasible and possible in all of the cadavers despite postmortem alterations.

Our study has several novel findings. We found a robust linear relation between $\triangle T F A$ and intracompartmental pressure. If only one leg is affected, this relation can be used to estimate intracompartmental pressure based on $\triangle T F A$. Each degree difference in TFA between the affected leg and the healthy leg is associated with an increase in intracompartmental pressure by approximately $4 \mathrm{mmHg}$. Second, side-to-side variability in TFA was small, indicating that measuring a difference from the corresponding spot on the other side (if available) may be of value. An absolute difference of $>10^{\circ}$ was observed with a low probability of $7 \%$ at a pressure of $10 \mathrm{mmHg}$. Third, interindividual variability in TFA was high, at low as well as elevated pressure levels. For example, at $30 \mathrm{mmHg}$ compartment pressure, TFA varied from $45^{\circ}$ in one cadaver to up to $89^{\circ}$ in another, at 50 $\mathrm{mmHg}$ from $50^{\circ}$ to $94^{\circ}$ respectively. This variation might be probably due to different body constitution and muscle mass among the small cohort of investigated cadavers. This issue can be easily overcome when the contralateral leg can be used as a reference, as we did in our study.

The anterior leg compartment pressure has important clinical relevance in ACS on its own [10, 26, 29, 30]. So far, ultrasound-guided evaluation of the anterior compartment has only been made in a physiological low-pressure range in healthy volunteers $[22,23]$. In this study, we defined only a single position of TFA

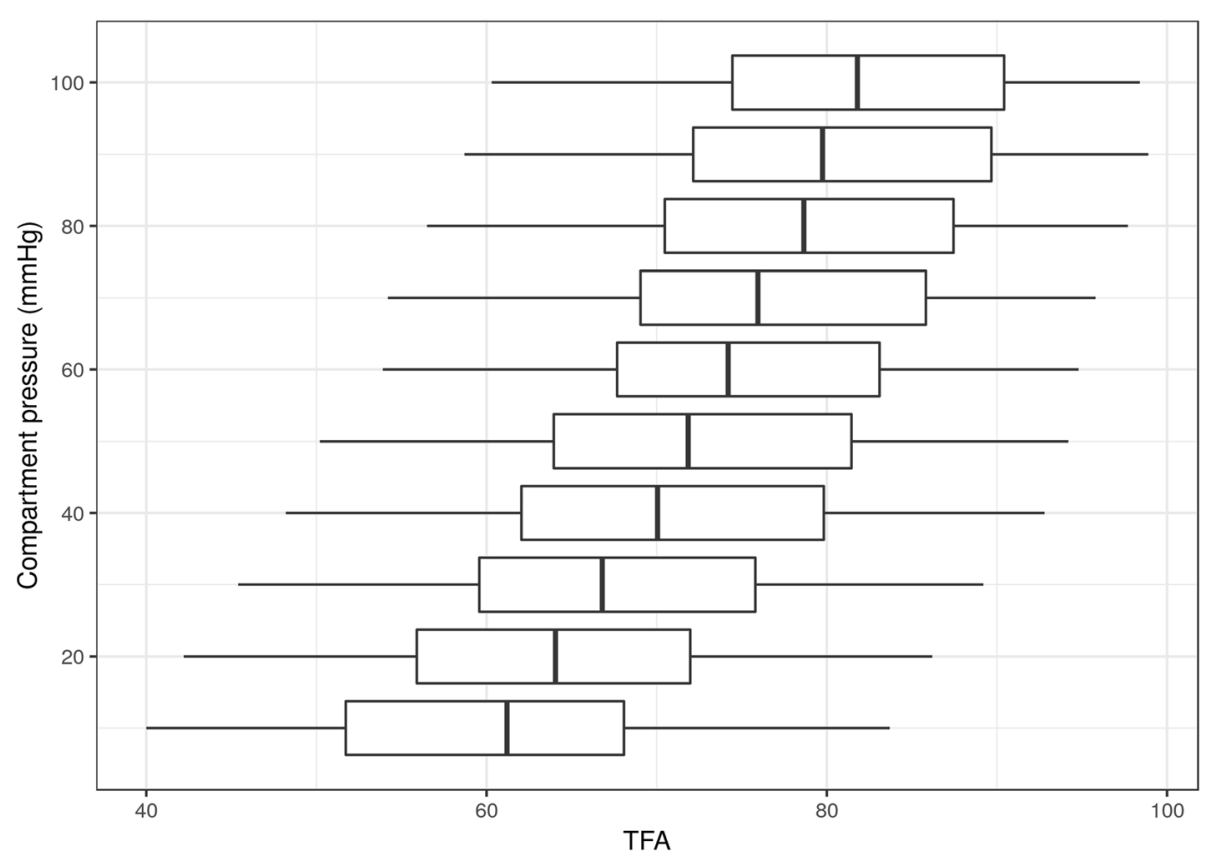

Fig. 3 Relation between tibia-fascia angle (TFA) measurements and pressure. Boxplots of TFA measurements at different pressure levels 


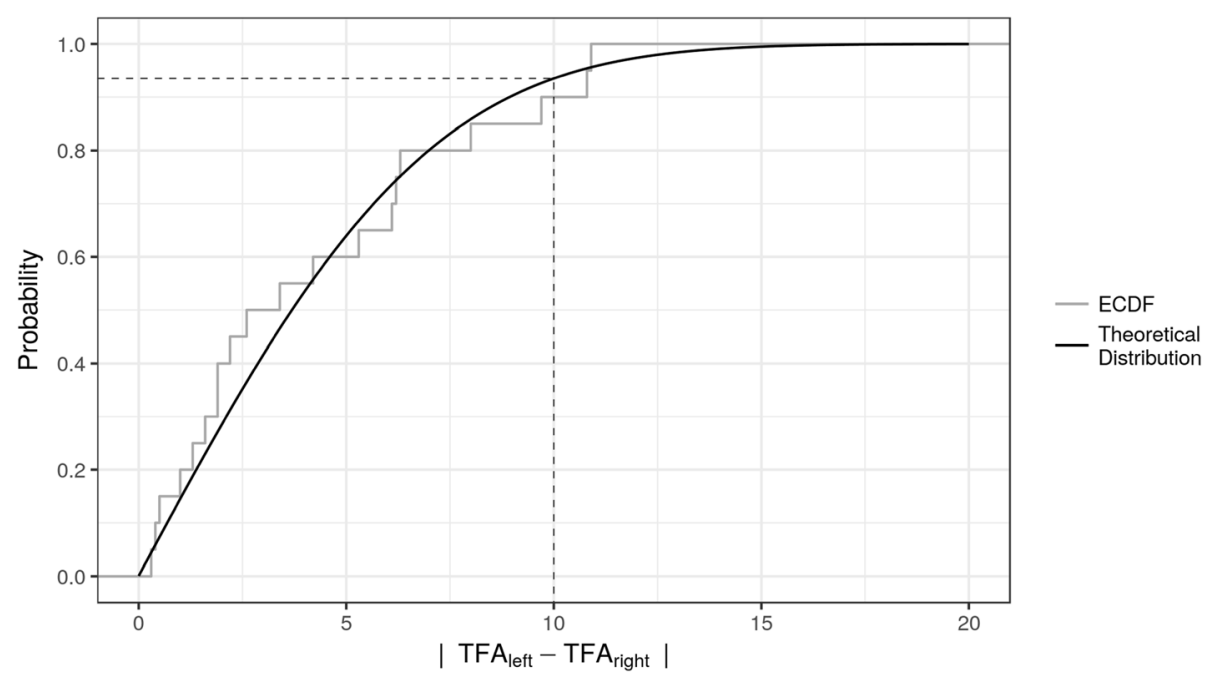

Fig. 4 Empirical cumulative distribution function (ECDF) and fitted theoretical distribution of absolute TFA (tibia-fascia angle) differences. ECDF (gray line) for absolute differences of the TFA between legs in each subject at a given $10 \mathrm{mmHg}$ pressure level, which we considered as relevant, and the fitted theoretical distribution function (black line). The dotted line shows given quantiles at an absolute TFA difference of $10^{\circ}$ based on the fitted theoretical distribution function

measurement between the middle and the proximal third of the distance from the tibial tuberosity to the intermalleolar line due to easy accessibility in view of possible further studies, for easy reproducibility, for standardized measurement and in expectation of maximal enlargement of the compartment at this level [22, 23]. Compared to previous experiments, we punctured the compartment $5 \mathrm{~cm}$ below and $5 \mathrm{~cm}$ above the side of ultrasound-guided measurement for infusion and continuous pressure monitoring to ensure desired intracompartmental pressure levels at the side of TFA assessment $[26,31-33]$.

This exploratory study has several limitations. Our inclusion was limited to old cadavers (median age of 81 years). They probably had reduced muscle mass, which may have led to systematically smaller TFA and/or different pressure values compared to a cohort of younger age or higher body mass index. Also, generalizability may be limited because this age group rarely suffers traumatic compartment syndrome. However, other causes of ACS at this age have been described [8]. The influence of increased pressure following rehydration of cadavers as well as post mortem alterations on TFA is unknown and may have biased the accuracy of our results [24]. Another limitation is that our investigation is limited to the anterior compartment on one single spot. The plausible relation of TFA of the anterior compartment with the deep posterior compartment pressure has not been tested in this study. Therefore, TFA cannot be used as a surrogate for the pressure in other compartments at this point. Another limitation is that our cadavers had no blood pressure. Therefore, we were not able to determine the confounding effect of blood pressure on TFA. This would be important since diastolic blood pressure may be a variable of interest in the decision-making process for surgical intervention. Furthermore, infusion of saline was used resulting in increased extracellular volume and subsequent pressure increase, whereas clinically compartment syndrome usually occurs due to cellular edema. The contact pressure of the ultrasound transducer on the compartment during measurement may have resulted in underestimation of TFA. Assessment of TFA was done on one standardized longitudinal level only. However, TFA may vary across different levels of the tibia. Pressure patterns along the compartment and in cases of fractured tibia were not investigated in this experimental study and may vary. Despite remarkable advantages, ultrasound is not always available and sonographic assessment is known to be skill and operator dependent. Even though, analysis of inter-observer variability revealed a substantial reliability (ICC 0.77) of this technique, intra-observer variability was not determined in this study. The findings of this exploratory study should not be used to change patient care at this stage; the method is unlikely to be used in clinical practice from now. However, this study should inform future studies in living patients with varying values of intracompartmental pressure.

\section{Conclusions}

We found that intracompartmental pressure of the anterior compartment of the calf can be well estimated by ultrasound-based $\triangle \mathrm{TFA}$ in this post mortem experiment. Our findings indicate that non-invasive TFA measurement is feasible and it is reasonable that this will hold true in real life, but the findings are too preliminary to be used in clinical practice now. 


\section{Appendix}

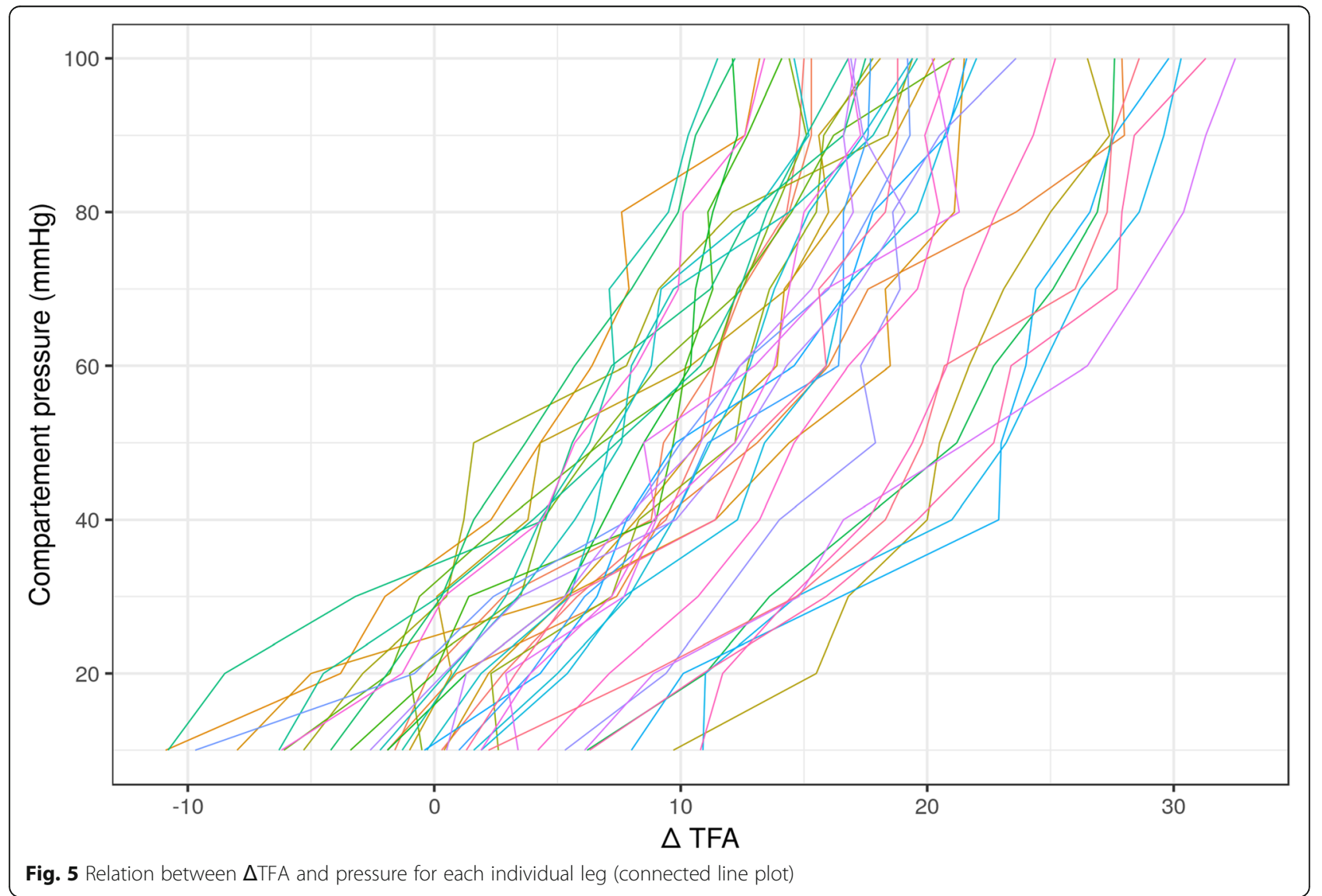

\section{Abbreviations}

ACS: Acute compartment syndrome; Cl: Confidence interval; ECDF: Empirical cumulative distribution function; ICC: Intraclass correlation coefficient; IQR: Interquartile range; SD: Standard deviation; TFA: Tibia-fascia angle; $\triangle T F A$ : Delta tibia-fascia angle

\section{Acknowledgements}

We acknowledge Hermann Gilly and Michael Röhrich for assistance with the development of the experimental model.

\section{Funding}

Not applicable

\section{Availability of data and materials}

Please contact author for data requests.

\section{Authors' contributions}

JM and SK designed the study. JM performed all experiments, collected the data, and drafted the manuscript. TG and $\mathrm{HH}$ analyzed and interpreted the data. JM, RP, UA, TG, SK, HH, and AD revised the manuscript and provided final approval of the submitted version. All authors read and approved the final manuscript.

\section{Ethics approval and consent to participate}

The local institutional review board (Ethics Committee of the Medical University of Vienna) approved this study (121/2010). Consent to participate was not applicable.

\section{Consent for publication}

Not applicable
Competing interests

The authors declare that they have no competing interests.

\section{Publisher's Note}

Springer Nature remains neutral with regard to jurisdictional claims in published maps and institutional affiliations.

\section{Author details}

1Department of Surgery, Division of General Surgery, Medical University of Vienna, Waehringer Guertel 18-20, A-1090 Vienna, Austria. ${ }^{2}$ Department of Surgery, Division of Plastic and Reconstructive Surgery, Medical University of Vienna, Vienna, Austria. ${ }^{3}$ Department of Biomedical Imaging and Image-guided Therapy, Medical University of Vienna, Vienna, Austria. ${ }^{4}$ Institute of Applied Statistics and Computing, University of Natural Resources and Life Sciences, Vienna, Austria. ${ }^{5}$ Department of Anaesthesiology and Intensive Care, AUVA, Linz, Austria. ${ }^{6}$ Department of Emergency Medicine, Medical University of Vienna, Vienna, Austria. ${ }^{7}$ Department of Anaesthesiology and General Intensive Care, Medical University of Vienna, Vienna, Austria.

Received: 30 November 2018 Accepted: 17 January 2019

Published online: 04 February 2019

\section{References}

1. Matsen FA, 3rd. Compartmental syndrome: an unified concept. Clinical orthopaedics and related research 1975:8-14.

2. Whitesides TE, Harada H, Morimoto K. Compartment syndromes and the role of fasciotomy, its parameters, and techniques.: CV Mosbey, St Louis; 1977. 
3. Matsen FA 3rd, Krugmire RB Jr. Compartmental syndromes. Surg Gynecol Obstet. 1978;147:943-9.

4. Matsen FA 3rd, Winquist RA, Krugmire RB Jr. Diagnosis and management of compartmental syndromes. J Bone Joint Surg Am. 1980;62:286-91.

5. Mauser N, Gissel H, Henderson C, Hao J, Hak D, Mauffrey C. Acute lower-leg compartment syndrome. Orthopedics. 2013;36:619-24.

6. Halpern AA, Nagel DA. Anterior compartment pressures in patients with tibial fractures. J Trauma. 1980;20:786-90.

7. Rorabeck CH, Macnab L. Anterior tibial-compartment syndrome complicating fractures of the shaft of the tibia. J Bone Joint Surg Am. 1976; 58:549-50.

8. Whitesides TE Jr, Heckman MM. The pathophysiology of compartment syndrome. Tech Orthop. 2012;27

9. Matsen FA 3rd, Clawson DK. The deep posterior compartmental syndrome of the leg. J Bone Joint Surg Am. 1975;57:34-9.

10. Sheridan GW, Matsen FA 3rd. Fasciotomy in the treatment of the acute compartment syndrome. J Bone Joint Surg Am. 1976:58:112-5.

11. Whitesides TE Jr, Haney TC, Harada H, Holmes HE, Morimoto K. A simple method for tissue pressure determination. Arch Surg. 1975;110:1311-3.

12. Whitesides TE, Haney TC, Morimoto K, Harada H. Tissue pressure measurements as a determinant for the need of fasciotomy. Clin Orthop Relat Res. 1975:43-51.

13. Mubarak SJ, Owen CA, Hargens AR, Garetto LP, Akeson WH. Acute compartment syndromes: diagnosis and treatment with the aid of the wick catheter. J Bone Joint Surg Am. 1978;60:1091-5.

14. Rorabeck CH, Castle GS, Hardie R, Logan J. Compartmental pressure measurements: an experimental investigation using the slit catheter. J Trauma. 1981;21:446-9.

15. Shadgan B, Menon M, O'Brien PJ, Reid WD. Diagnostic techniques in acute compartment syndrome of the leg. J Orthop Trauma. 2008;22:581-7.

16. Mars M, Hadley GP. Raised intracompartmental pressure and compartment syndromes. Injury. 1998;29:403-11.

17. Elliott KG, Johnstone AJ. Diagnosing acute compartment syndrome. J Bone Joint Surg Br. 2003;85:625-32

18. Sellei RM, Hingmann SJ, Weber C, Jeromin S, Zimmermann F, Turner J, et al. Assessment of elevated compartment pressures by pressure-related ultrasound: a cadaveric model. Eur J Trauma Emerg Surg. 2015;41:639-45.

19. Bloch A, Tomaschett C, Jakob SM, Schwinghammer A, Schmid T. Compression sonography for non-invasive measurement of lower leg compartment pressure in an animal model. Injury. 2018;49:532-7.

20. Challa ST, Hargens AR, Uzosike A, Macias BR. Muscle microvascular blood flow, oxygenation, $\mathrm{pH}$, and perfusion pressure decrease in simulated acute compartment syndrome. J Bone Joint Surg Am. 2017; 99:1453-9.

21. Budsberg SC, Shuler MS, Hansen M, Uhl E, Freedman BA. Comparison of NIRS, serum biomarkers, and muscle damage in a porcine balloon compression model of acute compartment syndrome. J Trauma Acute Care Surg. 2016;81:876-81.

22. Gershuni DH, Gosink BB, Hargens AR, Gould RN, Forsythe JR, Mubarak SJ, et al. Ultrasound evaluation of the anterior musculofascial compartment of the leg following exercise. Clin Orthop Relat Res. 1982:185-90.

23. Jerosch J, Geske B, Sons HU, Winkelmann W. The value of sonography in assessing intracompartmental pressure in the anterior tibial compartment. Ultraschall Med. 1989;10:206-10.

24. Lynch JE, Heyman JS, Hargens AR. Ultrasonic device for the noninvasive diagnosis of compartment syndrome. Physiol Meas. 2004;25:N1-9.

25. Wiemann JM, Ueno T, Leek BT, Yost WT, Schwartz AK, Hargens AR. Noninvasive measurements of intramuscular pressure using pulsed phaselocked loop ultrasound for detecting compartment syndromes: a preliminary report. J Orthop Trauma. 2006;20:458-63.

26. Heckman MM, Whitesides TE Jr, Grewe SR, Rooks MD. Compartment pressure in association with closed tibial fractures. The relationship between tissue pressure, compartment, and the distance from the site of the fracture. J Bone Joint Surg Am. 1994;76:1285-92.

27. Moed BR, Thorderson PK. Measurement of intracompartmental pressure: a comparison of the slit catheter, side-ported needle, and simple needle. Bone Joint Surg Am. 1993;75:231-5.

28. Shuler FD, Dietz MJ. Physicians' ability to manually detect isolated elevations in leg intracompartmental pressure. J Bone Joint Surg Am. 2010;92:361-7.

29. Gershuni DH, Mubarak SJ, Yaru NC, Lee YF. Fracture of the tibia complicated by acute compartment syndrome. Clin Orthop Relat Res. 1987:221-7.
30. McQueen MM, Christie J, Court-Brown CM. Acute compartment syndrome in tibial diaphyseal fractures. J Bone Joint Surg Br. 1996;78:95-8.

31. Boody AR, Wongworawat MD. Accuracy in the measurement of compartment pressures: a comparison of three commonly used devices. J Bone Joint Surg Am. 2005;87:2415-22.

32. Giannotti G, Cohn SM, Brown M, Varela JE, McKenney MG, Wiseberg JA. Utility of near-infrared spectroscopy in the diagnosis of lower extremity compartment syndrome. J Trauma. 2000;48:396-9 discussion 9-401.

33. Brooker AF Jr, Pezeshki C. Tissue pressure to evaluate compartmental syndrome. J Trauma. 1979;19:689-91.
Ready to submit your research? Choose BMC and benefit from:

- fast, convenient online submission

- thorough peer review by experienced researchers in your field

- rapid publication on acceptance

- support for research data, including large and complex data types

- gold Open Access which fosters wider collaboration and increased citations

- maximum visibility for your research: over $100 \mathrm{M}$ website views per year

At $\mathrm{BMC}$, research is always in progress.

Learn more biomedcentral.com/submissions 